\title{
A dose-finding study of IORT after radical prostatectomy (RP) in prostate cancer"
}

\author{
M. G. Petrongari, B. Saracino, P. De Carli, G. Albino, A. Soriani, S. Marzi, V. Landoni, A. Farella, \\ M. Gallucci, G. Arcangeli
}

\section{Purpose}

The rate of local recurrence aber RP ranges from $4 \%$ to $23 \%$ in $\mathrm{Tl} / 2$ and is grater than $40 \%$ in T3 tumors. Local recurrence occurs more frequently in the bladUeruretEral anastomosis (66\%), bladUer neck $116 \%$ ) and retrotrigonal area $113 \%$ ). A high risk of local foilure aLer RP includes patients with one or two risk factors (PSA > $10 \mathrm{ng} / \mathrm{ml}$, Gleason score (GS) $\geq 7$, positiveness in almost $2 / 3$ bioptic specimens, clinical stoge $\geq T 2 b$ ). Recent studies establisEed that the $\alpha / \beta$ ratio in prostate cancer is 1.5-2 Gy, i.d., lower than assumed for late responsive normal tissues. Therefore, the administration of a single dose should represent a more convenient irradiation method. We began a dose-escalation study (based on Fibonacci method) by employing IORT aker RP in patients with intermediate risk prostate cancer. Acute and late toxicities following escalating doses were monitored.

\section{Materials and methods}

18 pts received IORT at escalating doses of $16 \mathrm{~Gy}$, $18 \mathrm{~Gy}$ and $20 \mathrm{~Gy}$. The inclusive criteria were: age $<75$ years, clinical stoge $N O$ and lor 2 of the abovesaid risk factors. As toxicity was aSsent in further 10 pts treated with $20 \mathrm{~Gy}$, a dose escalation to $22 \mathrm{~Gy}$ was carried on, according to the planned strategy. IORT was delive-

Regina Elena Cancer Institute

Rome (Italy)

\# Trabajo presentado en las 3 as Jornadas Oncológicas Internacionales, Madrid 17-19 junio 2004. red aber RP, bladUerurethral anastomosis manufacture and bilateral obturator nodes sampling, by means of a dedicated Linac (Novac 7 Hitesys, highest energy 9 $\mathrm{MeV})$. The treatment port including the surgical bed and the anastomosis was irradiated through a sterile applicator with a $22^{\circ}$ angled edge and diameter of $4-6 \mathrm{~cm}$. The electron energy was selected in order to include all the structures in $90 \%$ isodose. An in vivo dosimetry was performed by introducing a Mosfet dosimeter in a rectal catheter and a Mosfet micro-dosimeter placed close to the anastomosis through a Foley catheter.

\section{Results and conclusions}

Our cases analysis showed a pathologic upgrade as to the clinical dota in $63.9 \%$ of cases, while a downgrade or an unchanged stoge was seen in $15.3 \%$ and $20.8 \%$, respectively. Positive margins were found in only 2 cases $(7 \%)$. Pathological GS compared to biopsy GS was hinher in $43 \%$ of cases, lower in 18\% and unchanned in a further $39 \%$. In all cases, in vivo dosimetry sFowed an absorSed dose to the rectum wall $<1 \%$. The presently available data show that the highest level of dose-finding was well tolerated, without any detectable rectal or vesical toxicity or anastomotic leakage protraction. A longest follow-up is necessary to verify the real impact of IORT in prostate cancer in term of late toxicity and loco-regional control. 